\title{
Policy watch: adapting to change in the animal care and use oversight environment
}

\author{
B. Taylor Bennett \& Matthew R. Bailey
}

In the $8^{\text {th }}$ edition of the Guide for the Care and Use of Laboratory Animals (Guide) the authors offer a succinct description of the oversight of the care and use of animal models in biomedical research in the United States. "The use of laboratory animals is governed by an interrelated, dynamic system of regulations, policies, guidelines, and procedures" (ref.1). By definition a dynamic system is always active or changing. There are many things that drive those changes and how an institution adapts to those changes in managing its Animal Care and Use Program (ACUP) will have a direct impact on its ability to assure its compliance and create an environment that facilitates their research program. In this article we will highlight some of the factors that drive that change and how the research community and its advocacy groups can and should respond to proposed changes.

Whenever there is a major change in the leadership in Washington there are also changes in the leadership of the Executive Branch Agencies, and those changes can influence the priorities of those agencies in ways that impact the oversight of animal based research. The recent election has resulted in the Republican Party controlling both houses of Congress and the White House, a change for which a public policy advocacy group such as the National Association for Biomedical Research (NABR) must respond. When a single party is in control of policy making in Washington, it is a safe assumption that national policy priorities will reflect the priorities of the party in control. While a wide variety of priorities for the new Administration were proffered on the campaign trail, any number

National Association for Biomedical Research, Washington, DC. Correspondence should be addressed to B.T.B. (btbdvm@yahoo.com). of them may be pursued and should be of concern to the biomedical research community. There has been much speculation about efforts to reduce overall regulatory burden in the United States. In addition, any changes to the size and make-up of the federal workforce could have an impact on federal inspections. Finally, the amount of federal funding approved for research projects has a direct impact on the number of available research jobs and the progress of science in the U.S. In order to help guide these priorities in a new Administration, and in the interest of sound public policy, the biomedical research community must first be cognizant of potential changes then make its concerns known to the advocacy groups charged with representing them.

In recent months there have been three opportunities for the research community to potentially effect change by responding to requests for comments published in the Federal Register including the USDA's Request for Information (RFI) (ID: USDA2016-0001-0045) concerning ways to reduce regulatory burden and their proposed De Minimis rule (ID: APHIS-2014-0059) and the FDA's proposed rule to amend the current Good Laboratory Practice (GLP) regulations (ID: FDA-2010-N-0548-0088).

The comment period for both the RFI and the De Minimis rule proposal have closed. A review of comments submitted in response to the RFI indicates a total of 73 comments were submitted; the majority of which addressed programs other than implementation of the Animal Welfare Act (AWA). There were only 18 comments submitted from the research community, which seems somewhat surprising given the level of concern expressed within the research community surrounding the issue of regulatory burden and how best to address it. While the substance of the comments submitted is important to provide the requesting agency with a basis for making decisions, the importance of the number of comments cannot be over stated and the lack of input on the part of the research community to this RFI does not bode well for realizing any changes to the Animal Welfare Regulations that could reduce the current regulatory requirements.

There were only a total of 29 comments for the proposed De Minimis rule of which merely four appeared to be from the research community. Two were from advocacy organizations and two from individuals. This was not surprising when one considers the proposed rule had little, if any, impact on the research community. However, it did include a technical issue related to the justification of a proposed change that was factually inaccurate; a point that both advocacy groups stressed and which 2 comments from the public highlighted.

Adapting to change in the dynamic oversight process in the U.S. is an important element of managing an ACUP, and a key factor in being successful is staying informed and participating in that process when the opportunity presents itself. Staying informed is relatively easy because of the availability of representatives from the regulatory, funding and accrediting organizations at a variety of meetings and with information regularly included in Lab Animal. Participating in the process is also relatively easy because of advocacy groups like NABR which monitor the oversight process and provide their members with necessary information to do so.

1. Institute for Laboratory Animal Research. Guide for the Care and Use of Laboratory Animals 8th edn. (National Academies Press, Washington, DC, 2011). 